5. S. Barber, C. C. Emett and T. D. Jones.- " Lighting in Mines: Illumination given by Portable Lamps at the Coal-Face." Transactions of the Institution of Mining Engineers, Vol. LXXXV, pp. 155-163, 1933 (or Colliery Guardian, Vol. CXLVI, pp. 734-736, 1933).

6. W. H. McMillan.- "The Practical Interpretation of Mine-Lighting Intensity Standards." Transactions of the Institution of Mining Engineers, Vol. LXXXIV, pp. 256-262, 1932 (or Colliery Guardian, Vol. CXLV, pp. 1171-1173, 1932).

7. Bureau of Mines, Washington: Schedule 6B-" Permissible Electric Cap Lamps," 1927. Revised 1929 and 1934.

8. C. W. Owings.- "Some Mine Lighting Practices in the United States." Transactions of the Illuminating Engineering Society, Vol. XXIX. pp. 47-63, 1934.

\title{
INJURIES OF THE EYE CAUSED BY SPORTS*
}

BY

STEPHEN DE GRósz

BUDAPEST

WE find numerous relations between the organ of sight and sport. In the first place we may investigate what claims must be laid on the functions of the eye in order to be successful in the various branches of sport. Thus, besides good central vision, great significance must be attached to a free field of vision, good stereoscopic sight and a good light sense. Doyne, whose observations: are published in detail in the "American Encyclopedia of Opthalmology," dealt with this question most exhaustively. More recently Sir David Munro gave a valuable review of the significance of the visual factor in sport, with especial regard to flying. Wirgman rendered account of the significance of errors of refraction in rifle practice; and it is conspicuous that two of the five prizewinners had an amblyopic eye. Good centering of glasses is very important. I will mention here that special spectacles are made for the use of marksmen. Another interesting question relates to what branches of sport the various eye patients may follow. In general, we may say that eye patients suffering from inflammatory conditions such as acute catarrh, iritis, etc., individuals inclined to haemorrhage, e.g., Eales's disease, should avoid all branches of physical culture. The highly myopic should also be excluded from sport, because of their tendency to detachment of the retina. We know these facts since Lindner and Rötth made experiments on the phantom. Individuals so inclined may sustain detachment not only through a minor, direct injury to the eye, but also indirectly, from a swift change of position, shock or physical strain.

* From the No. 1 Ophthalmological Clinic of the Royal Hungarian Peter Pázmány University. Director: Professor Dr. Emil de Grósz. 
In the history of detachment patients, an injury from tennis or football in childhood often plays a rôle. We would not debar glaucoma simplex patients from lighter sports; on the contrary, we may expect certain beneficial results from mild, regular physical exercise (Heiman) naturally, taking each case on its merits.

Along with the spread of hygienic living, the prevalence of sport is taking up greater dimensions from one day to another. We must hail this movement with joy if it really contributes to the improvement of the health of wide circles of the population. However, there is no doubt about the fact that we must qualify record breaking and excessive training as a harmful excrescence, since it produces only single champions and does not serve the purposes of general physical culture. The excessive training of youth might have harmful consequences. In order to avoid this, control by sport doctors is necessary. Parallel with the extension of sport we may expect the increase of sport injuries. To-day there is a separate science on damage caused by sport and this forms one chapter of accident surgery. This article essays to deal with injuries to the eye caused by sport, taking in order the various branches, and particularly emphasising the special injuries. In the same place we shall refer to those cases, which are not injuries in the strict sense of the term, and also to infection.

The eye may be affected directly (mechanically, by radiation) or it may be injured in an indirect manner. The traumata affecting the head may endanger the sight through haemorrhage or fracture, (fracture of the base of the skull or injury of the optic nerve).

This latter possibility exists in every branch of sport, so that in the following we shall discuss the direct injuries. These are generally contusional in character, the mechanism of which I shall not explain here as it is exhaustively discussed in the hand-books of ophthalmology (Kurzes Handbuch der Augenheilkunde; GraefeSaemisch); perforating injuries are less frequent (ski-staff).

First of all, however, we must digress in the direction of eye glasses. The sportsman wearing spectacles, is, to a certain degree, at a disadvantage with regard to his companions in some branches of sport; thus in swimming and water polo the splashing of the water upon his glasses disturbs his vision while the water may even carry his glasses away. For this reason, some competitors remove their glasses, which naturally is disadvantageous to them. The contact glasses, which in umbral (Zeiss) shade, with a lightabsorption of 75 per cent. may be taken into consideration for sport in high altitudes, endeavour to remedy this. These are chiefly advantageous for ametropic sporting people (in tennis, ski and motor sports) as they considerably improve the field of vision (Heine) and cannot be dimmed by vapour. Occasionally people 
suffering from a high degree of myopia may use them when bathing. On the rôle of protective glasses we will only say that for adherents to mountaineering, ski and motor sport, and aviation good protective glasses are indispensable since they absorb or rather reflect the harmful ultra-violet rays. On the latter principle is based Imre's reflector, the glass marked gold II and III, which affords first-class protection, especially in the sphere of sport. Protective goggles based upon absorption are the Umbral, with a light absorption of 50 per cent. in summer sports or at the seaside, and of 75 per cent. in high altitude sports, and the Ultrasin N.G. Here I must mention the excellent work of Rugg-Gunn on protective glasses. For tropical aviators he recommends Crookes' B. glasses fitted with a fine aluminium mirror. According to the method of Ritschl (Berlin) the metal is heated in a high vacuum, where it evaporates and is deposited on the lens placed at a distance of 10 centimetres. The glass is of an agreeable, neutral-grey tint and protects from infra-red and ultra-violet rays. On snow-fields he recommends Crookes' B.2, with a gold film made by sputtering, above which there is a covering-glass of uranium. By means of the fluorescence of the latter, by the reflection of the gold layer and the absorption of the glass they afford excellent protection against ultra-violet rays.

Now the problem crops up whether the possible breakage of the glasses serving optical purposes or protective purposes endangers the eye or not. We hear very little of such injuries, but they surely occur, and it certainly lends a feeling of security if sporting people have their glasses made of the so-called unbreakable glass, which does not break to splinters but merely cracks. If a layer of cellulose acetate, the refraction of which is nearly identical with that of glass, is placed between two lenses and then pressure and heat are applied we get the so-called unbreakable or laminated glass (Triplex, Splinter Proof, etc.). This can be made in such a way as to be merely $0.5 \mathrm{~mm}$. thicker than the corresponding common corrective glass. One layer acts as a "shock absorber" for the other, thus this glass is much more resilient than common glass. In case of an accident the two lenses hold each other and the splinters remain together. There is also a secret process for colouring them. This is an important invention-especially for golfers, aviators, motorists and other sporting people and especially for children! Such is Hamblin's Salvoc glass, also the French "aclastos," introduced by Bichelonne. To-day, faultless optical corrections and tints are manufactured. It is important that the frame and the glass should secure a wide field of vision for the player (Perivist Zeiss, Full Field Hamblin, principally in relation to tennis). Expressly for sport are made Hamblin's sport spectacles and Keeler's folding Perimet sport glasses and for ski-ing Hamblin's Everest goggles. 
Motor sport.-Besides the indirect injuries caused by motor accidents, lesions of the optic and the oculo-motor nerves caused by skull fractures, the glass splinters of the car also endanger the eye and its surroundings. The perforating injury of the eye ball with all its consequences, bleeding, cataract, infection, does not belong to the rarities. In the case mentioned by Morax enophthalmos followed the accident. As accidents happen on the high-road, it is necessary to give a preventive tetanus antitoxin inoculation, even if the eye only is injured (2,500 units). Since in cases of injuries from broken car windows the danger of gas-gangrene is great, it is advisable to supplement the former inoculation with gas-gangrene serum, e.g., I.G. Farben's Anaerobic serum* (Prophylactically $10-20 \mathrm{~cm} .{ }^{3}$ therapeutically $100 \mathrm{~cm} .^{3}$ intra-muscularly). We have not yet been able to demonstrate the intra-ocular glass splinter; Beauvieux succeeded in doing so on X-ray plates with soft rays. We must know, furthermore, that the lens fluoresces in ultra-violet light, but the glass splinter in it does not: therefore in this place we get a defect (Kleefeld). It is desirable that the wind-screen should be made of Triplex. A slight extra outlay upon the glass would prevent many injuries.

Among the ophthalmological relations of motor accidents, we may mention Rollet's two interesting cases. As the cause of repeated serious accidents in the evening he was able to demonstrate that the motor-bus drivers suffered from hemeralopia with intact fundus. According to police statistics, most accidents happen in the twilight. According to Rollet, the greater traffic and hurry to be expected at this time afford no explanation of this fact. Here the deficient vision, which presents itself in weak lighting, must play a rôle, and also the question of how soon sight returns after the glare caused by head-lights. Therefore Rollet demands that the drivers of fast vehicles (motor-buses, trains, aeroplanes) should be subjected to a preliminary photometric examination, as well as those causing evening accidents, especially in police cases. Those suffering from disturbed colour perception, on the other hand, are apt to mistake the signs of the municipal traffic lights. Accidents in the night are due to the oncoming chauffeur's not extinguishing the head-lights, thereby dazzling the other. In one of Rollet's cases the dazzled motorist ran into a tree and the splinters of the wind-screen cleft his eye in two; it was necessary to perform primary enucleation. Therefore it is advisable for drivers to wear Zeiss motoring-glasses in which there is an umbral layer thinning from above downwards so that when driving they can protect their eyes from being dazzled by the oncoming light by simply bending the head forward; at the top,

* A combination of antitetanic and anaerobic sera. 
the glasses have an absorption of 95 per cent. The measurements in connection with this were made by Hartinger and Fertsch from the standpoint of relative glare. Kühl confirmed these investigations: he found that in case of glare (Blendung, Uberstrahlung) the momentary use of light-moderating glasses is advisable.

At the session of the Belgian Ophthalmological Society, Bichelonne and his co-workers recommended yellow light for reflectors, i.e., cadmium glass, the advantages of which are: heightening of contrast, sharper sight, better distinguishing capacity and less fatigue. For motor-car drivers it has the following advantages : less glare, shorter re-adaptation and shortened time of psychomotoric reaction. Blondel also recommends reflectors with yellow light with sulphur-cadmium-selenite glass of $0.3-0.5 \mathrm{~mm}$. in thickness, from which electric-light bulbs may also be made. All the rays of light can be excluded under $520 \mu \mu$.

By excluding the very disturbing blue and violet rays reflected from the water drops in rain and fog, this light signifies a very great advantage. These same rays cause the glare also. With yellow light re-adaptation is quicker and there is a smaller reduction of visual purple. Besides this we may expect a better eyesight than with white light (monochromatic, 600 $\mu \mu$ ). Eye-glasses made of a similar glass would not be suitable.

Cazeneuve and his colleagues have called attention to a ver interesting cause of motor accidents. On examining 2,000 chauffeurs they found a difference of the pupils which is easily demonstrated if the patient fixes his sight first on a light point and then on a dark one. Generally the left pupil was more dilated. They also brought about anisocoria experimentally. The effect is believed to be due to the oil vapours, the exhaust gas, and chiefly the penetrating $\mathrm{CO}$ which may easily cause intoxication in a closed car. Knowledge of these phenomena is derived from war-time cases after a long motor transport. Anisocoria is brought about more easily in cases of alcoholism. The medullary centres form the point of attack; the result of the blood examination, and the blood pressure were normal. The Wassermann test was negative. In the case of three chauffeurs when the accidents were attributed to drunkenness (dizziness, diplopia) $\mathrm{CO}$ was demonstrated in the closed car. The loss of consciousness was due to this. However, anisocoria is a suitable symptom for the detection of these sensitive individuals. In doubtful cases, of course, the examination of the alcohol or the $\mathrm{CO}$ content of the blood would be the decisive factor. Bad ventilation, incorrect construction or a faulty gas-exhaust may be the causes of such poisoning.

Game shooting often causes eye injuries, seldom by the explosion of the gun but rather owing to the projectile, either directly or by ricochetting. Such injuries are well-known, therefore particulars 
are superfluous here. We merely wish to call attention to the early and exact localisation of the foreign body (Sweet) which, from the standpoint of the prognosis and operation, is of decisive importance. We may expect the reduction of these rather frequent accidents caused chiefly by small-shot, from the strengthening of sport discipline.

Angling is perhaps one of the most innocent pastimes. Nevertheless, we are acquainted with exceptional accidents here also, which we shall speak of more fully since they are not very common.

Hauptvogel, in 1923, mentioned a case at the Elschnig clinic, where the hook with the worm attached went through the limbus into the anterior chamber and entered the iris. By widening the entrance-opening with a Graefe knife the hook was successfully removed. The patient, a boy, aged 10 years, left the clinic with posterior synechia and 5/10 vision. In the same year Hermann treated a similar injury at Worms. The hook, which was cast a few metres away from the patient by his fishing companion, went through the cornea and the iris and buried its point in the lens. The longer branch of the hook, together with the bait, stuck in the palpebral aperture. Widening the wound with a lancet the hook was removed, nipping off the part of the iris which had become entangled therein. The conjunctiva was pulled over the wound. The patient left the clinic with traumatic cataract and $5 / 7$ vision. The other eye was amblyopic. In the case of Clarke, the hook, penetrating through the limbus, perforated the iris in two places, and its point stuck in the lens. The aqueous humour flowed out; the wound was enlarged and iridectomy performed. Owing to cataract caused by injury a discission was made (Queen's Hospital, Honolulu), and later the capsule was removed. With complete correction unimpaired conditions resulted. In one of Villard's eight cases a trout angler completely split his own cornea. In two of Borel's cases he could only remove the hook by cutting off the "harpoon" with watch-maker's clippers.

It is conspicuous that the above described cases proceeded without serious infection, though the nature of the injury renders infection probable. Prophylactic injection of tetanus antitoxin is advisable.

Probably the example of surgeons should be followed, who usually push the point through and clipping off the harpoon disengage the hook without much injury to the tissues. In our experiments on the pig's eye we pushed the point through the cornea after having made a small incision. We are convinced that this method inflicts the least injury.

The characteristic sport-complaint of alpine tourists is snow blindness, which is caused by the dense ultra-violet radiation reflected from the snow and ice-fields. Its slighter form shows 
lacrimation, photophobia, blepharospasm and irritation of the conjunctiva. The serious form shows excoriation of the cornea corresponding to the palpebral aperture. To avoid such painful phenomena, protective glasses are necessary (see above). This condition is identical with ophthalmia photo-electrica, to which welders and film actors are subject; treatment comprises : cool compresses, adrenaline and possibly dionine. I do not like to order cocaine because of its drying effect, and instead recommend 5 per cent. novocaine-adrenaline or psicaine ointment as a remedy $\overrightarrow{0}$ against the tormenting symptoms. Aqua zeozoni and corodenin drops are ineffective from the standpoint of light protection. Recently didymium ointment was recommended. According to Hess the harmful effect of light on snowfields is in connection with the thick layer of ozone extending over the high mountains, which layers select the harmful wave-lengths by way of diffraction.

Strebel has written on the eye injuries caused by ski-ing. $\mathrm{He}$ had many cases in Lucerne. We shall speak of his experiences in the following. The classical ski-staff injury of the eye is the contusion and rupture of the tendons, in the first place, of the inferior oblique which is always accompanied by permanent paralysis. Contusion of the external rectus with subconjunctival $\overrightarrow{0}$ haemorrhage and concussion of the retina are frequent. The alarme ing diplopia, however, ceases in a short time. The situation graver in the case of skull fractures, or the tearing of the periosteur and Tenon's fascia; for in such cases a cicatricial contracture arises which imitates the paralysis of the rectus externus. When the scar is freed the pseudoparesis ceases. This happens in cases of injuries to the inner canthus when, owing to the tearing of the canaliculi, permanent epiphora (with chronic catarrh) may ensue. If the tangential effect is stronger, the sinuses may be opened, sinusitis, fracture of the base, meningitis, and in case of a severer trauma, evulsion of the optic nerve may ensue. Finally, with a component rotating outwardly, a dislocation of the eyeball may occur while the edge of the optic foramen saws off the optic nerve. In a case of falling directly on the point of the staff the eyeball ruptured. According to Strebel, the great fault of the ski staffs is their being too long. In Switzerland they are 1.15 웅 metres in length and in Austria 2.10 metres, and their not being $\underset{\square}{\square}$ padded is also a source of danger. Therefore he demands that the end of every staff should be covered with a leather cushion $\sigma$ fixed through the strap bore, thereby securing the upper point of $N$ cleavage. The staffs with wooden buttons may easily cause rupture of the eye. His second demand is that the staff should be as short as possible and should at most reach the armpit when sliding. The long form should only be allowed for special cases, such as long distance running, military ski patrol; for beginners such? 
staffs are dangerous. He recommends staffs the size of a walking stick. We can identify ourselves with the first demand, but not with the second, because the short staffs may also cause injury: slipping when going up inclines and also the sportsman would not dispense with the indubitable advantages of the long staff. Herrenschwand (Innsbruck), whose views are similar to ours, attributes a rôle to the thickness of the staff; the thin and light hazelwood staffs (chiefly used for children) may cause a deep penetrating wound. It is advisable when sliding down hill, not to twist the strap around the wrist but to hold it freely, possibly with outstretched arm in a backward direction. In this manner we may avoid the characteristic distortions of the metacarpophalangeal joint of the thumb, as well as abdominal and face injuries, because, when falling, the staff is dropped. The habit of beginners, arising from a feeling of insecurity, to hold the staffs in front of them with bent arm, is dangerous. In alpine tours the ski staffs equipped with a pickaxe may also cause trouble. Strebel recommends that when crossing glaciers (with ropes) the point of the pickaxe should be wrapped up in a ski-stocking lined with straw when not in use. Even better would be a pickaxe which can be screwed off and placed in the knapsack. In one case the pickaxe caused a rupture of the choroid. A further possibility is to fall on to the point of the skis, therefore the desire that the ski should reach above the outstretched arm is correct, in other words, skis should be chosen individually. For the person taller than normal, the accustomed length may be relatively short. If the ski is suddenly arrested in course of the slide by obstruction in the ground or some fault the body is thrown forward and the end of the skis may easily be buried in the face of the runner. In one case it injured the orbit through the upper eyelid, causing prolapse of orbital fat.

The injuries discussed hitherto may be called typical. Herrenschwand communicates seven interesting cases; besides these, naturally, the eye may be injured in other winter sports, such as tobogganing. To this category belong injuries caused by the breaking of branches of trees and sport-equipment, which do not belong to the speciality of the branch of sport in question, but may occur in every sport which necessitates motion. We say that padding the handle of the staff is proper and should be insisted upon, but even this is no security against accidents. Even the most skilful sportsman may fall into a situation when the staff may endanger his face and this cannot even be avoided, because very often the defensive reflex brings it about in quickly changing positions. Owing to the great number of the components playing a rôle in accidents, it can hardlv be expected that the carrying out of the staff reform demanded by Strebel would render this 
sport essentially less dangerous. Perhaps suitable training would be beneficial from this standpoint.

On sleigh sport (toboggan, bobsleigh) I will only say that these may bring about indirect injuries, particularly injuries of the head, chiefly by running into trees; from this standpoint the $\frac{\overline{\bar{\sigma}}}{\mathrm{n}}$ skeleton sleigh is the most dangerous, where the sportsman lies face downwards with head in front. Injuries to the forehead oro temples " par contrecoup" "may lead to injuries of the optic nerve."

The forms of football injuries are the following : slight contu- $\vec{\circ}$ sions causing bleeding in the anterior chamber; this heals quickly. Graver possibilities are intra-ocular bleeding, sub-luxation of the $\omega_{\infty}$ lens, traumatic cataract or detachment of the retina. The ballo may cause the type of injury which ensues from collision with blunt objects.

In two cases Professor Gérard saw hyphaema; in a third the $\stackrel{\omega}{\vec{\omega}}$ traumatic cataract led to secondary glaucoma, therefore he removed the lens. Later on the hard bloodstained eye had to 9 be enucleated. This author, in his exceptionally interesting $\vec{z}$ article entitled "L'oeil et le sport," strongly reproves sporto excesses. We have seen an injury of easy progress from the breaking of eyeglasses : a young myopic physician wearing con- $\overrightarrow{0}$ cave glasses while playing football, the ball broke his glasseg; extensive lacerations of the lid was the result with slight cornegil abrasion. Gérard also dealt with tennis-ball injuries. Besidềso simple contusion he saw choroido-retinal rupture and haemorrhage into the vitreous, and in one case detachment of the retina. In general, with football the danger is less owing to the size of the $e_{\propto}^{\Phi}$ ball than with tennis for the bony edge of the orbit prevents deep $\overrightarrow{\vec{O}}$ penetration. A young professional's right eye was hit with a马 football; his eyesight became bad immediately. There was haemorrhage in the vitreous and at the posterior pole, retinal and? preretinal haemorrhages extending to the periphery were seen $\frac{0}{0}$. Between the blood-spots of the retina bluish-white areas were to be seen (traumatic oedema). After a week the haemorrhages in the vitreous disappeared, while those of the retina showed ao diminishing tendency.

The injuries caused by tennis balls are : suffusion of the sub-o conjunctiva, abrasion of the cornea, hyphaema, rupture of the iris and choroid, and even rupture of the eye-ball. Fejér, at the 24th Congress of the Hungarian Society of Ophthalmology, N referred to a case of recurrent keratitis, and further two casesn of injuries causing a fissure of the iris and rupture of the choroid.N Fazakas saw concussion of the retina arise, against which he recommends inhalation of amyl nitrite. Tóth saw lesions of the corneal epithelium and Ditrói central scotoma with photopsia.

The player standing by the net doubtless is more exposed to injury. 
Thus extensive abrasion of the epithelium of the cornea and serious internal haemorrhage occur in some cases. The former cases generally regenerate quickly and the latter are quickly absorbed. A few of our cases: 1. A man wearing concave glasses was injured by a tennis ball so that the glass broke and its splinters caused a perforating trauma to the cornea pinching in the iris, which was released in course of the recovery. Three weeks afterwards the wound was healed, leaving a scar and a round pupil. This was a rare and fortunate accident. 2. A swift ball hit the player in the right eye causing extensive abrasion of the cornea. Cured in one week. 3. In another of our cases the ball caused intra-ocular bleeding, this, increasing, developed into glaucoma. The blood was absorbed without interference.

We believe it probable that the cause of contusional deterioration of sight is concussion of the retina and perhaps we should see more often traumatic oedema of the retina if the examination of the injured person could be effected immediately. From the standpoint of the eye the most dangerous sport is boxing. The especially frequent cases of haematoma of the eyelids and haemorrhage under the conjunctiva are of no consequence, for in spite of their alarming appearance they heal quickly. If accompanied by fracture, subcutaneous emphysema occurs which increases on blowing the nose. The fissure of the skin of the eyelid along the orbital bone is frequent, on which occasion the entire eyelid may tear off. It is of graver consequence if a cataract arises, without opening the eyeball, or detachment of the retina occurs.

Sedan describes the following conditions in four professionals (three champions). Very sluggish photomotor reflex, deformed pupils, mydriasis, the cause of which are the fine ruptures of the stroma extending to the lacunae sometimes with irido-dialysis. He believes it to be a characteristic occupational disease after several years in the ring. With another boxer he found permanent exophoria, mydriasis and sluggish reflexes. Still one other after fracture of the skull had rupture of the sphincter of the iris, with deformed pupils and complete absence of reflexes. Syphilis, of course, was excluded. A third had similar changes of the iris accompanied by detachment of the retina. Jokl and Guttmann, in their interesting compilation which deals with the neurological examination of boxers, mention temporary paralysis of the ocular muscles among the direct consequences, headache, disturbance of speech, etc.

With regard to fencing we have little to say. The faultless mask, the foil with a button, all afford sure protection for the face of the fencer. Yet a few cases are known when the foil, making an aperture in the mask, has run through the eye, or leaving the eye-ball intact has run beside it, backwards into the 
orbit, cutting through the optic nerve in its depths causing primary atrophy of same (Emil de Grósz, Kretz). By penetrating through the top of the orbit it may even injure the brain. In such cases the button also breaks on the mask. King Henry II of France died in a similar manner in 1559, when he fought in a tournament, "la joute," on horseback, with a lance against Montgomery.

In the sphere of water sport (swimming, rowing, water polo) we do not find any particulars regarding injury to the eye. The $\vec{\circ}$ catarrh of the conjunctiva sustained in closed swimming pools is probably due to a filterable virus and is of genital origin. The $\vec{\omega}$ unilateral acute follicular conjunctivitis, accompanied by pre- $\frac{\partial}{0}$. auricular lymphadenitis, has proved itself to be an exceptionally obstinate disease, which only improves after long treatment, though it has no serious consequences. This fact distinguishes it $\stackrel{\omega}{+}$ from trachoma. This disease, belonging to the group of inclusional $\vec{\infty}$ conjunctivitis, frightens many people away from closed swimming $ᄋ$ pools. Only the daily changing of the water or treatment with chlorine could dispel this certainly justifiable fear. In this 3 direction a great future awaits oligodynamic silver which sterilises in minute quantities (katadyn process).

A unique injury caused by a golf club was described by Moras $\stackrel{\oplus}{\oplus}$ at one of the sessions of the French Society of Ophthalmologist On the fundus of the blind eye situated in the depths of the orbit there were extensive haemorrhages and much depigmentation.

The general frequency of trauma in hockey is 33 per cent. (Glass). The special injuries are caused by the stick, 37 per cent., and the ball, 43 per cent., the remainder belong to the indirect group (falling), $43-46$ per cent. of the injuries are to the head; most frequently the surroundings of the eyebrow. In the injury of the latter the stick plays a rôle of 17 per cent., the ball 26 per cent. (bruises and cuts). Anyhow, the injuries are chiefly to the soft parts so that the player is soon able to return to his sport.

Owing to its beneficial effect upon physical culture and to the fact that it incurs little danger, Arnold believes hockey to be $\mathrm{a} \dot{\mathrm{\delta}}$ branch of sport to be recommended from a sport-medical stand-point.

We have been informed of a quite extraordinary trachoma epidemic in the United States. Patton and Gifford treated eight wrestlers from Omaha who caught trachoma from each other while $\stackrel{\circ}{\circ}$ wrestiling. From the anamneses the succession of the passing of the inoculation was precisely established. According to the explanation of the professional heavy-weight champions and the ex-champions, during the bout, when the referee was not looking, they vigorously massaged each other's eyes according to ancient $\stackrel{\mathbb{\Phi}}{\mathbb{D}}$ custom, the aim of which was to bring about Ashner's oculo- $?$ cardiac reflex. 
To bring about this reflex we press the eye-ball with eyelids closed for 10 seconds upon which, in case of excessive excitability of the vagus, bradycardia occurs, when, in certain cases, the pulse stops for a few seconds. A positive reflex signifies lability of the pneumogastric and has the same effect as carotid sinus-pressure (Hering). It may be used to stop paroxysmal tachycardia. In order to study the oculocardiac reflex Pruche made an electrocardiogram. He found that not only the frequency of auricular and ventricular contractions changed, but that the electro-cardiographic appearance of several cardiac revolutions was altered (shortening of the PR complex, auricular-ventricular dissociation, etc.). Complete heart block may also occur.

In the meantime they infected each other's eyes with the virus of trachoma by means of perspiration. After being enlightened the wrestlers were willing to warn their antagonists of this and to join forces in the campaign against the infection. According to Patton, they were, without exception, "a splendid bunch of fellows." Darier mentions three similar infections from Paris, which occurred in course of a wrestling match. He believes that the wrestler, suffering from trachoma, wipes the tears and the mucus out of his eyes, in the heat of combat, with his fingers, thus spreading the contagion to his adversary. Zentmayer saw two similar cases in Philadelphia : an amateur and a professional. MacCallan, in his presidential address in London, May, 1935, stated: "It is not generally known that nearly all professional wrestlers have trachoma." He thinks that Rugby football is able to disseminate this infection if a member of the team is infected.

Of the numerous varieties of athletics, spear-throwing is the only one which I wish to mention. In Schneider's case the spear, thrown from behind, struck the person in question just as he was turning round. It penetrated the corner of the eye, tearing off the rectus internus, causing a rupture of the choroid. Three months later a brain abscess developed, which healed after operation. Thus the spear caused a stab on the brain through the dura as well as injuring the wall of the frontal sinus.

The Sandow, which used to be popular a few decades ago, and is still cultivated, also takes its victims. A young man with his foot in the expander was practising the exercise of stretching the spring. The handle slipped off his foot and flew into his face in such an unfortunate manner that it caused partial disinsertion of the iris and traumatic cataract with complete deterioration of sight (Villard).

In a similar case of Gérard the eye of a young girl had to be removed owing to rupture of the eye-ball. In another case haemorrhage into the vitreous occurred through the breakage of the elastic band and the instrument flying into the patient's face. In every 
one of these three cases, one handle was in the hand and the foot

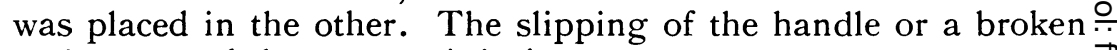
spring caused these grave injuries.

A short time ago we had the occasion to see an extraordinarily rare accident in skating (Horay). A seven-year-old girl fell on the ice in such a manner that the skate tore her eye. The bleeding $\frac{\bar{c}}{\frac{5}{7}}$ uvea prolapsed through a sharp-edged wound about $2 \mathrm{~cm}$. in length $\stackrel{\Phi}{\varnothing}$ running through the cornea on to the sclera. We had to enucleate $ळ$ the collapsed eye-ball. Here we must mention that the same may $\overrightarrow{0}$ be said of ice hockey in general as of grass hockey with the exception that in place of the flying ball the disc, sliding along the ice, $\vec{\sigma}$ cannot so easily cause trouble. On the other hand, the greater $\frac{\mathscr{O}}{0}$. speed attained by the player causes more falls and collisions, $\stackrel{\circ}{\circ}$ thereby carrying indirect injuries in its train. In one case the? disc striking the player in the eye caused a retention cyst lined ${ }_{-}^{\omega}$ with stratified cylindrical epithelium in the lower fornix, which $\vec{\infty}$ arose from the piece of epithelium torn off by the blow ando inoculated beneath the conjunctiva (Panneton). A boy of $1 i \cdot$ years was struck by his own stick through an inadvertent move- 3 ment of a fellow-player. On examination there was an extensive corneal abrasion, traumatic iridoplegia and hyphaema. The slight ${ }_{\overrightarrow{ }}$ protrusion of the eye-ball suggested retrobulbar haemorrhage. The initial rise of tension subsided spontaneously and full covery took place in three weeks.

I wish to communicate an injury caused by an arrow. A schoo teacher, 20 years of age, was wounded in the eye by an arrow which his companion shot by accident from a distance of $12 \frac{\mathrm{Q}}{\Omega}$ metres. A long wound was caused in the suffused lower eyelid, $\stackrel{\varrho}{\vec{P}}$ a lacerated wound of $1 \mathrm{~cm}$. within and under the conjunctiva and을 an unequally deep anterior chamber, iridodonesis, subluxation of the lens. Three days after the injury the hyphaema of $1 \mathrm{~mm}$., whichor appeared on the following day, was completely absorbed; there was slight trembling of the iris with normal tension.

In the course of the Franco-German Rugby match played at Budapest International Olympic Games for Students, 1935, ai German player was accidentally struck in the right eye by an₹ opponent, causing the outer canthus to split and a contusedo wound $2 \mathrm{~cm}$. in length on the conjunctiva. The wounds healeds per primam after suturing, but the tearing of the rectus externuso. caused permanent paralysis of the muscle. Later on advancemento of the muscle will be performed.

I saw emphysema of the orbit arise in the case of a young girin during a "friendly" basket ball match. She was struck in the face by her opponent. On the X-ray picture one can easily discern the air in the orbit and a linear fracture of the lamina papyracea The eye-ball was intact. 
If we peruse the described sport injuries, we must say that some of these are rare contingencies, even curiosities such as occur in angling and Sandow, but some of them are typical occurrences with which we must reckon (boxing, ski). The question is whether they are avoidable or not. Alas, only partially. The protection against excessive light in high altitudes has already sunk into public knowledge. The number of infections in closed swimming pools, including aural infections, can be reduced by stricter control of the water. We have discussed in detail the manner of protection in ski sport. There would be one more possibility to diminish the number of accidents, i.e., increased sport discipline, which, for instance, would reduce the number of hunting accidents. And here belongs the problem of sport training also.

I hope that by writing these lines I shall succeed in awakening the interest of ophthalmological and sport-medical circles in a somewhat neglected sphere. The outlining of sport injuries can only be an advantage to physical culture since by knowing them they can be avoided, if only partially. This work serves this purpose.

\section{REFERENCES}

1. Arnold.-Deutsche Med. Wochenschr., No. 52, 1931.

2. Beauvieux.-Arch. d'Ophtal., p. 529, 1927.

3. Bichelonne.-Belg. Ophthal. Soc., 1932.

4. Bichelonne, Monnier and Mouton.-Ref. Zentralbl.f.d. ges. Ophthal., Vol. XXXIII, p. 592.

5. Blondel.-Zentralbl.f. d. ges. Ophthal., Vol. XXXI, p. 503.

6. Borel.-French Ophthal. Soc., 1934.

7. Cazeneuve, Tenon and Neveu.-Ref. Zentralbl. f. d. ges. Ophthal., Vol. XXIX, p. 584.

8. Clarke.-Amer. Jl. of Ophthal., Vol. VI, p. 763.

9. Darier.-Ref. Brit. Jl. of Ophthal., Vol. VIII, p. 181, 1924.

10. Ditrói.-Hung. Ophthal. Soc., XXIVth Meeting.

11. Fazakas.-Ibid.

12. Fejér.-Ibid.

13. Gérard.-La Clin. Ophtal., Oct.-Nov., 1926.

14. Hauptvogel.-Klin. Monatsbl. $f$. Augenheilk., Vol. LXX, p. 170.

15. Heiman.-Zeitschr. f. Augenheilk., Vol. LXXI.

16. Hermann.-Klin. Monatsbl. f. Augenheilk., Vol. LXXI, p. 211.

17. Herrenschwand.-Zeitschr. f. Augenheilk., Vol. LXIII, p. 142.

18. Jokl and Guttmann.-Münch. Med. Wochenschr., p. 15, 1933.

19. Kühl.-Ref. Zentralbl. $f$. d. ges. Ophthal., Vol. XXXIII, p. 9.

20. Morax.-French Ophthal. Soc., p. 391, 1934.

21. Munro.-Trans. Ophthal. Soc. U.K., Vol. LI, p. 323.

22. Panneton.-Ref. Zentralbl.f. d. ges. Ophthal., Vol. XXXIII, 101.

23. Patton.-Amer. Jl of. Ophthal., p. 545, 1922.

24. Pruche.-Ref. Zentralbl. f. d. ges. Ophthal., p. 285, 1934.

25. Rohrschneider.-Zentralbl. f. Aerzt. Fortbild, Vol. XXX, p. 464

26. Rollet.-Arch. d'Ophtal., Vol. LI, p. 72.

27. Rugg-Gunn.-Brit. Jl. of Ophthal., p. 65, 1934.

28. Sedan.-Ophthal. Soc., Paris, 934, Febr.

29. Strebe1.-Deutsche Med. Wochenschr., p. 595, 1921.

Schweiz Med. Wochenschr., p. 381, 1930.

30. Schneider.-Ref. Zentralbl. $f$. $d$. ges. Ophthal., Vol. XXVI, p, 111.

31. Tóth.-Hung. Ophthal. Soc., XXIVth Meeting.

32. Villard.-French Ophthal. Soc., 1934.

33. Wirgmann.-Lancet, Jan., 1935.

34. Zentmayer.-A rch. of Ophthal., p. 235, 1934. 